\title{
THE EFFECT OF EURYCOMA LONGIFOLIA JACK ON SPERMATOGENESIS IN ESTROGEN-TREATED RATS
}

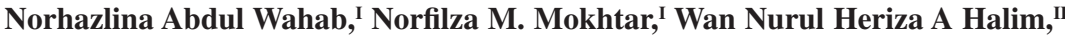 \\ Srijit Das ${ }^{\text {III }}$
}

doi: 10.1590/S1807-59322010000100014

\begin{abstract}
Norhazlina AW, Norfilza MM, Halim WNHA, Das S. The effect of eurycoma longifolia jack on spermatogenesis in estrogentreated rats. Clinics. 2010;65(1):93-8.
\end{abstract}

INTRODUCTION: There is little data concerning the ability of Eurycoma longifolia Jack (EL) to reverse the inhibitory effects of estrogen on testosterone production and spermatogenesis. The aim of the present study was to determine the effect of EL on testicular histology and sperm count in estrogen-treated male rats.

METHODS: Adult male Sprague-Dawley rats weighing 200-250 g were divided into four groups of six rats each. Group A (control) was given solvent in the same manner as the treated groups were given EL. Group B was treated with EL (8 mg/kg body weight) orally. Group $\mathrm{C}$ was treated with estradiol ( $\mathrm{E}_{2}$ ) (intramuscular dose of $500 \mu \mathrm{g} / \mathrm{kg}$ body weight), and group D received a combined treatment of oral EL and intramuscular $\mathrm{E}_{2}$. After fourteen consecutive days of treatment, rats from all groups were sacrificed and subjected to spermatogenic and epididymal sperm cell counts.

RESULTS: The spermatogenic cell count in the $\mathrm{E}_{2}$-treated group was significantly decreased as compared to the control ( $\mathrm{p}<$ $0.05)$ and $E_{2}+E_{2}$-treated groups $(p<0.05)$. A similar finding was found for the epididymal sperm count; the $E_{2}$-treated group had a significant decrease in the count compared to the control $(\mathrm{p}<0.05)$ and $\mathrm{EL}+\mathrm{E}_{2}$-treated groups $(\mathrm{p}<0.05)$. Rats that were treated with EL alone exhibited significantly higher sperm counts and sperm motility when compared to the control group ( $\mathrm{p}<0.05$ ).

CONCLUSIONS: EL extract acts as a potential agent for reversing the effects of estrogen by increasing spermatogenesis and sperm counts in rats after fourteen consecutive days of treatment.

KEYWORDS: Eurycoma longifolia Jack; Estrogen; Testis; Spermatogenesis; Anatomy; Histology.

\section{INTRODUCTION}

Eurycoma longifolia Jack (EL), a herb found in SouthEast Asia, has been widely used in traditional medicine. The plant belongs to the Simaroubaceae family and is known locally as 'Tongkat Ali' or 'Pasak Bumi' in Malaysia and Indonesia, respectively. ${ }^{1} \mathrm{EL}$ has been shown to possess anticancer, ${ }^{2}$ antibacterial, ${ }^{3}$ cytotoxic, ${ }^{4,5}$ aphrodisiac $^{6,7}$ and

I Department of Physiology, Faculty of Medicine, UKM Medical Molecular Biology Institute (UMBI), Universiti Kebangsaan - Malaysia.

II Department of Biomedical Science, Faculty of Allied Health Sciences, Universiti Kebangsaan - Malaysia.

III Department of Anatomy, Faculty of Medicine, Universiti Kebangsaan Malaysia.

Email: kakmeah@yahoo.com.sg

Tel.: 00600392897575

Received for publication on September 14, 2009

Accepted for publication on October 26, 2009 antimalarial effects. ${ }^{8,9}$

Reduced fertility in males is related to hormonal, malerelated diseases, such as varicocele, cryptorchidism and testicular cancer, or severe exposure to chemicals, such as pesticides that contain lindane,${ }^{10,11}$ and drugs for the treatment of cancer. ${ }^{12,13}$ Hormonal disturbances that may lead to infertility include low plasma levels of testosterone or gonadotropins or high plasma levels of estrogen. ${ }^{14}$ Indeed, there are reports that phytoestrogen diets may cause reductions in male fertility. ${ }^{15,16}$

Estrogen exerts its effect on spermatogenesis by two mechanisms. Estrogens may act directly on Leydig cells to suppress testosterone production or through negative feedback on gonadotropin-releasing hormone secretion. ${ }^{17}$ Some studies have reported on the presence of estrogen receptors in germ cells ${ }^{18}$ or Sertoli cells. ${ }^{19}$ In males, 
endogenous estrogens are synthesized from androgens by the enzyme aromatase..$^{20,21}$ The estrogens produced in males are known to regulate testicular steroidogenesis and spermatogenesis; ${ }^{22}$ however, to date, the role of estrogen in germ and Sertoli cells is poorly understood and requires further investigation.

EL was reported to be a potential agent that could increase male sexual competency ${ }^{6}$. Previous animal studies have strengthened this conclusion with the observation that EL is a potential stimulator of male sexual character in Sprague-Dawley rats. This natural compound also possesses some effects on hormones, showing evidence of marked androgenic action. However, to the best of our knowledge, earlier studies have not explored the action of EL on testisretrieved sperm counts in comparison to such counts in estrogen-treated rats.

Therefore, the primary aim of the present study was to determine if EL extract could counteract the adverse effects of estrogen on spermatogenesis and improve fertility in Sprague-Dawley rats. The results of the present study could define the use of EL in the future as a potential natural treatment for low male fertility.

\section{METHODS AND MATERIALS}

Prior ethical clearance was obtained from the Universiti Kebangsaan Malaysia Animal Care and Use Committee (UKMACUC), and the experiment was conducted at the histology laboratory, Department of Anatomy, Universiti Kebangsaan Malaysia (UKM).

\section{Animals, chemicals and treatment}

Twenty-four fertile male Sprague-Dawley rats, each weighing 200-250 g (between four and six months of age) were obtained from the UKM animal unit. Animals were caged in the animal house and maintained at $27-30^{\circ} \mathrm{C}$. The animals had free access to rat chow and drinking water. The animals were divided into four groups of six rats each. Group A served as the control and received normal saline by oral gavage; group B was treated with EL at a dose of $8 \mathrm{mg} /$ $\mathrm{kg}$ body weight orally; group $\mathrm{C}$ was treated with estradiol at a dose of $500 \mu \mathrm{g} / \mathrm{kg}$ body weight intramuscularly (i.m.), and group D was treated with $8 \mathrm{mg} / \mathrm{kg}$ body weight of EL orally with an i.m. injection of $500 \mu \mathrm{g} / \mathrm{kg}$ body weight of estradiol (Sigma Chemical Co, USA). All treatments were administered daily at $0900 \mathrm{hrs}$ and were continued for fourteen days. On the $15^{\text {th }}$ day, the animals were sacrificed using an intravenous injection of an anesthetic agent, and one of the testes and its associated epididymis were dissected and removed for further analysis.

\section{Eurycoma longifolia Jack extract preparation}

The aqueous dried extract of EL, in the form of powder, was obtained from the Department of Biochemistry, Universiti Malaya, Malaysia. The extract was dissolved in normal saline to a final concentration such that each rat received $\mathrm{EL}$ at a dose of $8 \mathrm{mg} / \mathrm{kg}$ body weight in a volume of $0.5 \mathrm{ml}$. Estradiol (Sigma Chemical Co, USA) was first diluted using ethanol and olive oil (1:9 volume) to obtain the desired concentration. The dispensing volume was $0.1 \mathrm{ml}$.

\section{Histological analysis}

A routine paraffin fixation for the testicular tissues was performed to determine histological changes in the testis following treatment with either EL, estradiol or a combination of both after fourteen days of treatment. The tissues were first fixed in $10 \%$ formalin for one week, followed by a dehydration procedure using a series of graded alcohol mixtures. The dehydrated tissue was then immersed in xylene for two hours. Tissues were then embedded in paraffin and were cut at a thickness of $6 \mu \mathrm{m}$. The tissues were mounted on slides and stained by immersing them in hematoxylin solution. The slides were then immersed in acid alcohol solution and rinsed under running tap water to remove excess hematoxylin. The slides were dipped in eosin solution and then dehydrated through a series of graded alcohols. Finally, the tissues were mounted with dibutyl phthalate xylene (DPX).

\section{Epididymal sperm motility and counts}

Epididymal sperm counts were performed to assess the rats' reproductive status. The epididymal tissue was cut into small pieces and diluted with normal saline. A small aliquot of the diluted tissue was placed on a slide and examined using a light microscope and photographed. We used a hemocytometer to calculate the number of sperm in ten randomly selected quadrants.

\section{Statistical analysis}

The data were expressed as mean \pm standard deviation (SD). Differences between the mean values were determined using the Student's $\mathrm{t}$ test. $\mathrm{P}$ values of less than 0.05 were considered statistically significant.

\section{RESULTS}

\section{Histological analysis}

The histological observations of the seminiferous 
tubules of group B (EL-treated rats) were similar to those of group A (control); the tubules were condensed with spermatogenic cells, and the lumen was filled with spermatozoa. Spermatogonia were present along the basement membranes, and the nuclei were round and compact (Fig. 1 A \& B). Under higher magnification (200x magnification), the primary spermatocytes and spermatogonia were predominantly normal. The interstitial tissues were also normal (Fig. 1 A \& B).

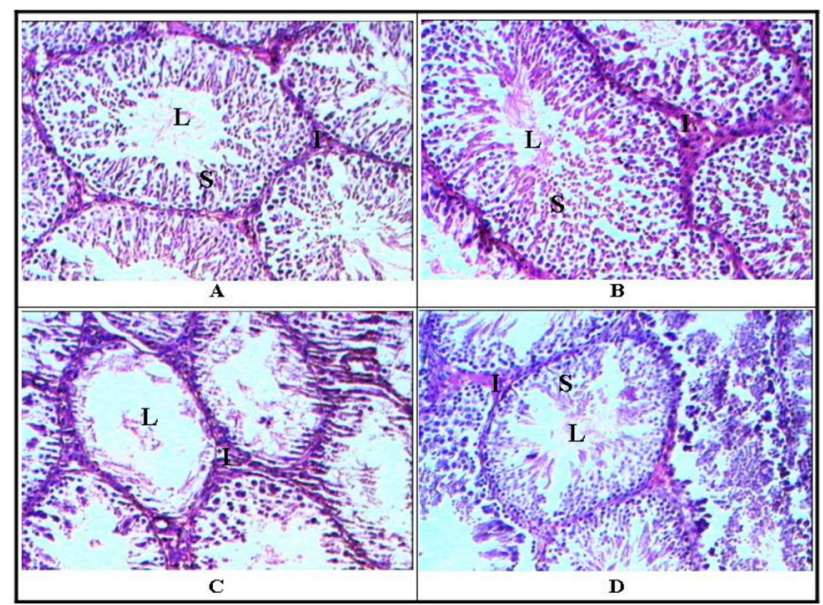

Figure 1 - The testicular histology of the control (A), Eurycoma longifolia Jack-treated (B), estradiol-treated (C) and combined EL and estradiol-treated (D) rats. Letters in the micrographs indicate the lumen of the seminiferous tubule (L), spermatogenic cells (S) and interstitial tissue (I) (200x magnification)

Seminiferous tubules from group C (estradiol-treated rats) showed a marked decrease in spermatogenic cells, and the lumens of some tubules were empty (Fig. 1 C). In contrast, rats that received a combination treatment of EL and estradiol (Fig. 1 D) showed a marked increase in spermatogenic cells as compared to group C (Fig. 1 C).

Fig. 2 shows the spermatogenic cell counts for each of the treated groups and the control group. The results showed that spermatogenic cell counts were markedly increased in the seminiferous tubules of group B as compared to group A $(\mathrm{p}<0.05)$, and group $\mathrm{D}(\mathrm{p}<0.05)$. Of note, in group $\mathrm{C}$, this parameter was significantly reduced as compared to group A $(\mathrm{p}<0.05)$ and group $\mathrm{D}(\mathrm{p}<0.05)$.

\section{Sperm motility}

Fig. 3 shows the percentages of motile sperms from all groups, which were obtained by microscopic examination at room temperature $\left(37^{\circ} \mathrm{C}\right)$. Group B (EL-treated) rats had a higher percentage of motile sperms as compared to the control group (group A) $(p<0.05)$. No significant changes were observed in other groups.

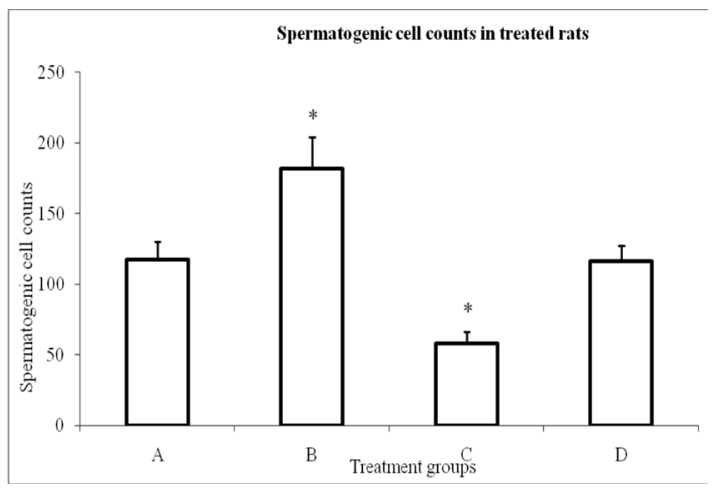

$* \mathrm{p}<0.05$ as compared to group A (control)

$* \mathrm{p}<0.05$ as compared to group D (EL + estradiol)

Figure 2 - Spermatogenic sperm counts. The values are shown as the mean \pm standard deviation. Group B (EL treated) shows a marked increase in the spermatogenic cell count, compared to group A (control) and group D (EL + estradiol). The sperm count is significantly reduced in group C (estradioltreated rats) compared to group A and group D

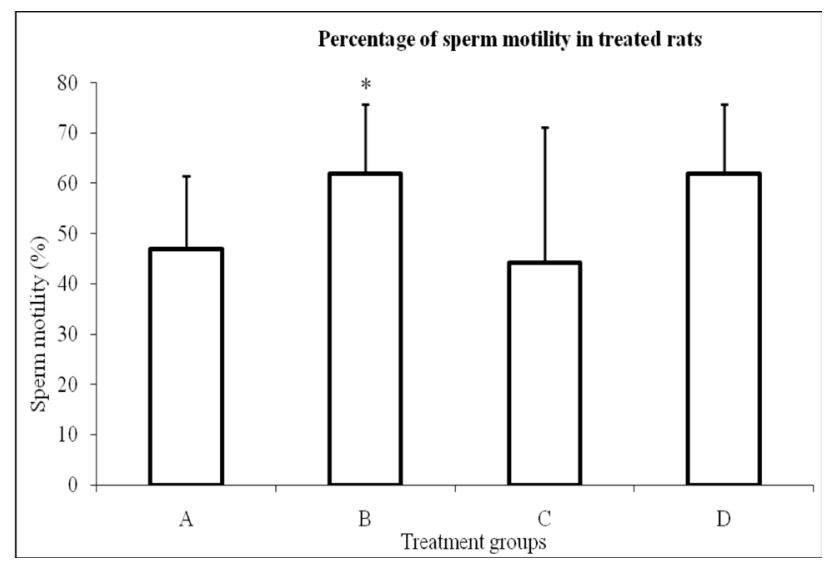

*p $<0.05$ as compared to group A (control)

Figure 3 - The percentage of motile sperms in rats treated with EL (B), estradiol (C) and a combination of EL and estradiol (D) compared to the control (A). The values are shown as the mean \pm standard deviation. Group $\mathrm{B}$ shows a marked increase in the percentage of motile sperms compared to group A.

\section{Epididymal sperm count}

Epididymal sperm counts were markedly decreased in group $\mathrm{C}$ (estradiol-treated rats) as compared to group A (control) $(\mathrm{p}<0.05)$ and group D $(\mathrm{p}<0.05)$ (Fig. 4). In contrast, rats that were treated with EL (group B) showed a significant increase in sperm counts as compared to group A $(\mathrm{p}<0.05)$ and $\mathrm{D}(\mathrm{p}<0.05)$.

\section{DISCUSSION}

The use of traditional medicines for treating various conditions or diseases is a common practice in the Asian continent, especially in Malaysia. This is due to the belief 


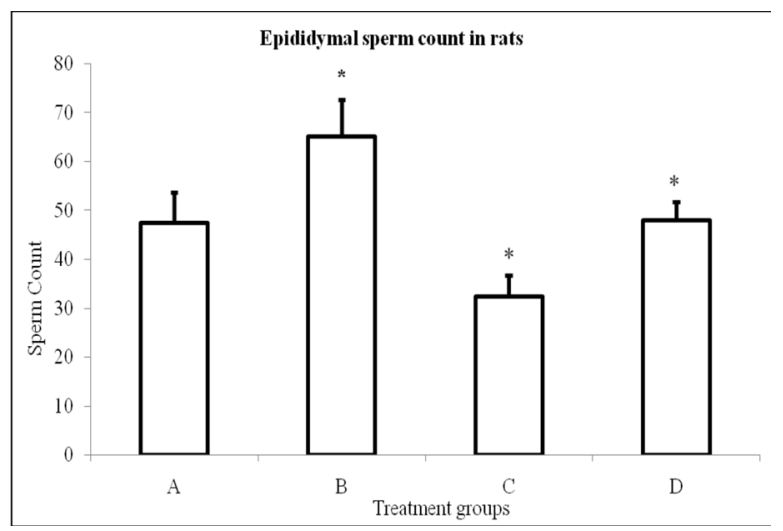

$* \mathrm{p}<0.05$ as compared to group A (control)

$* \mathrm{p}<0.05$ as compared to group D (EL + estradiol)

Figure 4 - Epididymal sperm counts in rats treated with EL (B), estradiol (C) and a combination of EL and estradiol (D), compared to the control (A). The values are shown as the mean \pm standard deviation. Group B shows a marked increase in the spermatogenic cell count compared to the control (group A) and group D (EL + estradiol). The cell count is significantly reduced in group $\mathrm{D}$ (estradiol-treated rats) compared to group $\mathrm{A}$ and group $\mathrm{D}$

among Asian populations in having a holistic approach towards the treatment of diseases, such as infertility. ${ }^{23} \mathrm{~A}$ study in China reported that the use of traditional herbal preparations accounted for nearly $30-50 \%$ of the total medicines consumed (WHO media center). Many traditional herbal preparations are used to increase libido, sexual performance and muscle strength in males. ${ }^{24}$ Interestingly, the British Journal of Sports Medicine published a research article in which EL was reported to increase muscle size and strength as compared to the placebo. ${ }^{25}$ This finding perhaps, has led to the belief that males can increase their muscle strength and size by consuming EL.

In the present study, we looked into the protective action of EL in the setting of estrogen exposure. To the best of our knowledge, there are no studies that have focused on the action of EL in estrogen-exposed subjects. For decades, estrogens have been considered to be female hormones. However, various research studies have proposed an essential role for estrogens in the male reproductive tract. Both in males and females, androgens are converted into estrogens by aromatization in androgen target tissues and in circulation. Estrogen can act by binding with its receptor, which is located in Leydig cells, germ cells and spermatozoa. This data points to the physiological role of estrogen in steroidogenesis and spermatogenesis. ${ }^{26,27}$ However, there are few studies that have explored the exposure of male rats to estrogenic compounds or to high doses of phytoestrogens, which can result in germ cell apoptosis, thereby reducing epididymal sperm counts. ${ }^{28}$ Of note, this effect was reported to be independent of the influence of the hypothalamo-gonadal axis. ${ }^{15,29}$
The action of estrogen on male reproductive organs has been studied extensively. A study by Kolasa described the presence of estrogen receptors on the epithelium of the epididymis. ${ }^{30}$ In this same study, the author reported that epithelial cells of the epididymis contain $5 \alpha$-reductase, an enzyme that can catalyze the irreversible conversion of testosterone into the most active and chief androgen of the epididymis, dihydrotestosterone. ${ }^{30}$ Incidentally, dihydrotestosterone plays an important role in preserving and regulating the function of the epididymis. The present study did not look into the levels of this enzyme, but the increase in sperm count and spermatozoa due to EL treatment are surely underlined by the activity of this enzyme.

Research studies have shown that apoptosis is involved in testicular germ cell loss in animals and humans, which could play a vital role in male fertility. ${ }^{31}$ In the present study, EL may have inhibited the apoptosis that would have resulted from the estrogen exposure. The increase in spermatogenic cells and the percentage of motile sperms in the EL-treated group, as well as the EL combined with estradiol-treated group, demonstrated the protective actions of EL. If this is the case, then in situations where there is an excess of estrogen or deficiency in testosterone, EL may be able to act as a remedy for the condition. This may open new doors for the treatment of testosterone-deficient or hyperestrogen states in those who search for infertility treatments.

According to the literature, there has been much interest in the general population concerning the use of natural herbal treatments, as well as other products, such as tiger penis, monkey brains and rhinoceros horns ${ }^{23}$ for the treatment of infertility in males. The use of natural products derived either from plant or animal sources may be important for the treatment of male infertility.

Of concern, an earlier study conducted on males between 40 and 70 years of age in Brazil, Italy, Japan and Malaysia showed the prevalence of erectile dysfunction to be $22 \%$ and $34 \%$ in Malaysia and Japan, respectively. ${ }^{32}$

The aphrodisiac properties of EL are well documented and have been proven through previous studies. ${ }^{33}$ Some research studies have reported that EL is able to increase the frequency of sexual intercourse, the duration of sexual intercourse and the number of ejaculations in animals. ${ }^{34,35}$ However, the dosages used in various studies were much higher than that used in the present study. The present study shows that even low doses of EL are sufficient to increase sperm counts in normal rats and in estrogen-treated rats.

Prior studies have reported on the direct involvement of estrogens in the regulation of spermatogenesis. ${ }^{36}$ Investigations of the expression level of the P450 aromatase enzyme have demonstrated that the process of spermatogenesis is controlled by estrogen. ${ }^{36}$ Research studies 
have even highlighted the influence of environmental agents (xenobiotics) on the male and female reproductive systems in animals. ${ }^{37}$ These xenobiotic agents are recognized to have a significant impact on steroidal hormones and can even influence multiple signaling pathways and estrogen responsive genes. ${ }^{37}$ Admittedly, the present study did not look into P450 aromatase enzyme levels, signaling pathways or the estrogen gene expression, which could have been influenced by the steroidal hormones and EL, thereby explaining the results of the present study.

\section{CONCLUSION}

Testosterone is important for normal male fertility, and a hyperestrogenic state may not be conducive for ideal testicular function. EL heightens testicular functioning and inhibits the effects of an excessive estrogen state. Therefore, EL can be used as a supplement for treating fertility conditions where there is testosterone deficiency or estrogen excess.

\section{REFERENCES}

1. Osman A, Jordan B, Lessard PA, Muhammad N, Haron MR, Riffin NM, et al. Genetic diversity of Eurycoma longifolia inferred from single nucleotide polymorphisms. Plant Physiol. 2003;131:1294-301.

2. Tee TT, Cheah YH, Hawariah LP. F16, a fraction from Eurycoma longifolia jack extract, induces apoptosis via a caspase-9-independent manner in MCF-7 cells. Anticancer Res. 2007;27:3425-30.

3. Farouk AE, Benafri A. Antibacterial activity of Eurycoma longifolia Jack. A Malaysian medicinal plant. Saudi Med J. 2007;28:1422-4.

4. Kuo PC, Damu AG, Lee KH, Wu TS. Cytotoxic and antimalarial constituents from the roots of Eurycoma longifolia. Bioorg Med Chem. $2004 ; 12: 537-44$

5. Kuo PC, Shi LS, Damu AG et al. Cytotoxic and antimalarial betacarboline alkaloids from the roots of Eurycoma longifolia. J Nat Prod. 2003;66:1324-7.

6. Ang HH, Lee KL, Kiyoshi M. Sexual arousal in sexually sluggish old male rats after oral administration of Eurycoma longifolia Jack. J Basic Clin Physiol Pharmacol. 2004;15:303-9.

7. Ang HH, Ngai TH, Tan TH. Effects of Eurycoma longifolia Jack on sexual qualities in middle aged male rats. Phytomedicine. 2003;10:5903 .

8. Chan KL, Choo CY, Abdullah NR, Ismail Z. Antiplasmodial studies of Eurycoma longifolia Jack using the lactate dehydrogenase assay of Plasmodium falciparum. J Ethnopharmacol. 2004;92:223-7.

9. Sholikhah EN, Wijayanti MA, Nurani LH, Mustofa. Stage specificity of pasak bumi root (Eurycoma longifolia Jack) isolate on Plasmodium falciparum cycles. Med J Malaysia. 2008;63 Suppl A:98-9.

10. Saradha B, Vaithinathan S, Mathur PP. Lindane induces testicular apoptosis in adult Wistar rats through the involvement of Fas-FasL and mitochondria-dependent pathways. Toxicology. 2009;255:131-9.

11. Traina ME, Rescia M, Urbani E, Mantovani A, Macrì C, Ricciardi C, et al. Long-lasting effects of lindane on mouse spermatogenesis induced by in utero exposure. Reprod Toxicol. 2003;17:25-35.

12. Feagins LA, Kane SV. Sexual and reproductive issues for men with inflammatory bowel disease. Am J Gastroenterol. 2009;104:768-73.

13. Meistrich ML. Male gonadal toxicity. Pediatr Blood Cancer. 2009;53:261-6

14. Pinto ME, Vilamaior PS, Taboga SR, Goes RM. Exposure of young rats to high estrogen doses leads to degeneration of elongated spermatids. Tissue Cell. 2008;40:31-42.
15. Assinder S, Davis R, Fenwick M, Glover A. Adult-only exposure of male rats to a diet of high phytoestrogen content increases apoptosis of meiotic and post-meiotic germ cells. Reproduction. 2007;133:11-9.

16. Sliwa L. [The influence of soybean riches of phytoestrogens diet in mouse testis histological structure]. Folia Med Cracov. 2005;46:121-31.

17. Rochira V, Zirilli L, Genazzani AD, Balestrieri A, Aranda C, Fabre B, et al. Hypothalamic-pituitary-gonadal axis in two men with aromatase deficiency: evidence that circulating estrogens are required at the hypothalamic level for the integrity of gonadotropin negative feedback. Eur J Endocrinol. 2006;155:513-22.

18. Lambard S, Carreau S. Aromatase and oestrogens in human male germ cells. Int J Androl. 2005;28:254-9.

19. Mutembei HM, Pesch S, Schuler G, Hoffmann B. Expression of oestrogen receptors alpha and beta and of aromatase in the testis of immature and mature boars. Reprod Domest Anim. 2005;40:228-36.

20. Brodie A, Inkster S. Aromatase in the human testis. J Steroid Biochem Mol Biol. 1993;44:549-55.

21. Carreau S, Lambard S, Delalande C, Denis-Galeraud I, Bilinska B, Bourguiba S. Aromatase expression and role of estrogens in male gonad: a review. Reprod Biol Endocrinol. 2003;11:1-35.

22. Miura T, Miura C, Ohta T, Nader MR, Todo T, Yamauchi K. Estradiol17beta stimulates the renewal of spermatogonial stem cells in males. Biochem Biophys Res Commun. 1999;264:230-4.

23. Low W-Y, Tan H-M. Asian traditional medicine for erectile dysfunction. The Journal of Men's Health \& Gender. 2007;4:245-50.

24. Ang HH, Lee KL, Kiyoshi M. Eurycoma longifolia Jack enhances sexual motivation in middle-aged male mice. J Basic Clin Physiol Pharmacol. 2003;14:301-8.

25. Hamzah S, Yusof A. The Ergogenic Effects of Eurycoma Longifolia Jack: A Pilot Study. Br J Sports Med. 2003;37:464-70.

26. Carreau S, de Vienne C, Galeraud-Denis I. Aromatase and estrogens in man reproduction: a review and latest advances. Adv Med Sci. 2008;53:139-44.

27. Carreau S, Silandre D, Bourguiba S, Hamden K, Said L, Lambard S, et al. Estrogens and male reproduction: a new concept. Braz J Med Biol Res. 2007;40:761-8.

28. Baek IJ, Yon JM, Lee SR, Jin Y, Kim MR, Ahn B, et al. Effects of endocrine disrupting chemicals on expression of phospholipid hydroperoxide glutathione peroxidase mRNA in rat testes. J Vet Sci. 2007;8:213-8. 
29. Tarrago-Castellanos CR, Garcia-Lorenzana CM, Diaz-Sanchez V, Velazquez-Moctezuma J. Gonadotrophin levels and morphological testicular features in rats after different doses of the phytoestrogen coumestrol. Neuro Endocrinol Lett. 2006;27:487-92.

30. Kolasa A. Epididymis in an experimental model of DHT deficiency: immunolocalization of ERalpha and ERbeta in rat epididymal epithelial cells. In vivo and in vitro studies. Ann Acad Med Stetin. 2006;52:13-21.

31. Orazizadeh M, Hashemitabar M, Khorsandi L. Protective effect of minocycline on dexamethasone induced testicular germ cell apoptosis in mice. Eur Rev Med Pharmacol Sci. 2009;13:1-5.

32. Nicolosi A, Glasser DB, Moreira ED, Villa M. Prevalence of erectile dysfunction and associated factors among men without concomitant diseases: a population study. Int J Impot Res. 2003;15:253-7.
33. Rowland DL, Tai W. A review of plant-derived and herbal approaches to the treatment of sexual dysfunctions. J Sex Marital Ther. 2003;29:185205.

34. Ang HH, Lee KL. Effect of Eurycoma longifolia Jack on orientation activities in middle-aged male rats. Fundam Clin Pharmacol. 2002;16(6):479-83.

35. Ang HH, Lee KL. Effect of Eurycoma longifolia Jack on libido in middle-aged male rats. J Basic Clin Physiol Pharmacol. 2002;13:249-54.

36. Schön J, Blottner S. Estrogens are involved in seasonal regulation of spermatogenesis and sperm maturation in roe deer (Capreolus capreolus). Gen Comp Endocrinol 2008;159:257-63.

37. Danzo BJ. Environmental xenobiotics may disrupt normal endocrine function by interfering with the binding of physiological ligands to steroid receptors and binding proteins. Environ Health Perspect. 1997;105:294-301. 